\title{
Absorption, distribution, metabolism and excretion of selenium following oral administration of elemental selenium nanoparticles or selenite in rats
}

Löschner, Katrin; Hadrup, Niels; Hansen, Marianne; Alves Pereira, Sónia Cristina; Gammelgaard, Bente; Møller, Laura Hyrup; Mortensen, Alicja; Lam, Henrik Rye; Larsen, Erik Huusfeldt

\section{Published in:}

Metallomics

Link to article, DOI:

10.1039/C3MT00309D

Publication date:

2014

Document Version

Publisher's PDF, also known as Version of record

Link back to DTU Orbit

Citation (APA):

Löschner, K., Hadrup, N., Hansen, M., Alves Pereira, S. C., Gammelgaard, B., Møller, L. H., Mortensen, A., Lam, H. R., \& Larsen, E. H. (2014). Absorption, distribution, metabolism and excretion of selenium following oral administration of elemental selenium nanoparticles or selenite in rats. Metallomics, (6), 330-337.

https://doi.org/10.1039/C3MT00309D

\section{General rights}

Copyright and moral rights for the publications made accessible in the public portal are retained by the authors and/or other copyright owners and it is a condition of accessing publications that users recognise and abide by the legal requirements associated with these rights.

- Users may download and print one copy of any publication from the public portal for the purpose of private study or research.

- You may not further distribute the material or use it for any profit-making activity or commercial gain

- You may freely distribute the URL identifying the publication in the public portal 


\section{Metallomics}

Cite this: Metallomics, 2014 6,330

Received 15th October 2013, Accepted 16th December 2013

DOI: 10.1039/c3mt00309d

www.rsc.org/metallomics

\section{Absorption, distribution, metabolism and excretion of selenium following oral administration of elemental selenium nanoparticles or selenite in rats $\dagger$}

\author{
Katrin Loeschner, ${ }^{a}$ Niels Hadrup, ${ }^{a}$ Marianne Hansen, ${ }^{a}$ Sonia A. Pereira, ${ }^{a}$ \\ Bente Gammelgaard, ${ }^{\mathrm{b}}$ Laura Hyrup Møller, ${ }^{\mathrm{b}}$ Alicja Mortensen, ${ }^{\mathrm{a}}$ Henrik Rye Lam ${ }^{\mathrm{a}}$ \\ and Erik H. Larsen*a
}

\begin{abstract}
A suspension of nanoparticles of BSA-stabilized red amorphous elemental selenium (Se) or an aqueous solution of sodium selenite was repeatedly administered by oral gavage for 28 days at $0.05 \mathrm{mg} \mathrm{kg}^{-1} \mathrm{bw}$ per day (low dose) or at $0.5 \mathrm{mg} \mathrm{kg}^{-1}$ bw per day (high dose) as Se to female rats. Prior to administration, the size distribution of the Se nanoparticles was characterized by dynamic light scattering and transmission electron microscopy, which showed that the particles' mean diameter was $19 \mathrm{~nm}$ and ranged in size from 10 to $80 \mathrm{~nm}$. Following administration of the high dose of Se nanoparticles or selenite the concentration of Se was determined by ICP-MS in the liver, kidney, urine, feces, stomach, lungs, and plasma at the $\mu \mathrm{g} \mathrm{g}^{-1}$ level and in brain and muscle tissue at the sub- $\mu \mathrm{g} \mathrm{g}^{-1}$ level. In order to test if any elemental Se was present in the liver, kidney or feces, an in situ derivatization selective to elemental Se was performed by treatment with sulfite, which resulted in formation of the selenosulfate anion. This Se species was selectively and quantitatively determined by anion exchange HPLC and ICP-MS detection. The results showed that elemental Se was present in the livers, kidneys and feces of animals exposed to low and high doses of elemental Se nanoparticles or to selenite, and was also detected in the same samples from control animals. The fraction of Se present as elemental $\mathrm{Se}$ in livers and kidneys from the high dose animals was significantly larger than the similar fraction in samples from the low dose animals or from the controls. This suggested that the natural metabolic pathways of Se were exhausted when given the high dose of elemental Se or selenite resulting in a non-metabolized pool of elemental Se. Both dosage forms of Se were bioavailable as demonstrated by the blood biomarker selenoprotein $\mathrm{P}$, which was equally up-regulated in the high-dose animals for both dosage forms of Se. Finally, the excretion of Se in urine and its occurrence as Se-methylseleno- $N$-acetyl-galactosamine and the trimethylselenonium-ion demonstrated that both dosage forms were metabolized and excreted. The results of the study showed that both forms of Se were equally absorbed, distributed, metabolized and excreted, but the detailed mechanism of the fate of the administered elemental Se or selenite in the gastro-intestinal tract of rats remains unclear.
\end{abstract}

\section{Introduction}

Selenium (Se) and its metabolites occur in organisms from a range of phyla including microorganisms, fungi, plants, animals and humans and is incorporated into Se-proteins such as the antioxidant enzymes glutathione peroxidases or selenoprotein-P

\footnotetext{
${ }^{a}$ National Food Institute, Technical University of Denmark, Mørkhøj Bygade 19, DK-2860 Søborg, Denmark. E-mail: Ehlar@food.dtu.dk; Fax: +453588 7448; Tel: +4535887631

${ }^{b}$ Department of Pharmacy, University of Copenhagen, Universitetsparken 2, DK-2100 Copenhagen, Denmark

$\dagger$ Electronic supplementary information (ESI) available. See DOI: 10.1039/ c3mt00309d
}

(SelP), a transport protein for Se. Current reports on the metabolism of Se have proposed that the metabolic cycle and excretion from humans include both inorganic and organic molecular species of Se present at various oxidation states including $-2,+2,+4$ and $+6 .{ }^{1}$ The formation of elemental Se (oxidation state $0, \mathrm{Se}^{0}$ ) has less often been studied as part of metabolic processes. ${ }^{2}$ Nevertheless, $\mathrm{Se}^{0}$ has been reported to occur in soils where microbes drive the redox cycle between on one hand the oxidized species selenate (Se(vI)) and selenite $(\mathrm{Se}(\mathrm{Iv}))$ and on the other hand the reduced $\mathrm{Se}^{0} .{ }^{3}$ Furthermore, $\mathrm{Se}$ (Iv) can be reduced to nanometer-sized particles of $\mathrm{Se}^{0}$ by fungi, which expelled the nanostructures through their cell membrane as a protective mechanism. ${ }^{4}$ Following enrichment 
of a culture of Lactobacillus bulgaricus with Se(Iv), amorphous $\mathrm{Se}^{0}$ nanoparticles ( $\mathrm{Se}^{0} \mathrm{NPs}$ ) were formed outside and inside their cytosol, and this $\mathrm{Se}^{0}$-enriched culture was suggested as a safe dietary source of Se. ${ }^{5}$ Transmission electron microscopy (TEM) with element-selective energy-dispersive X-ray fluorescence (EDX) proved to be a convenient tool in these studies for imaging of the $\mathrm{Se}^{0} \mathrm{NPs}$ and to provide evidence of their identity.

The absorption rate of $\mathrm{Se}^{0}$ obtained from bacteria was tested and showed a modest availability in chickens at $2 \%$ of that of Se(Iv). ${ }^{6}$ Synthetically made $\mathrm{Se}^{0} \mathrm{NPs}$ have been selectively engineered as novel Se supplements by derivatizing their surface with bioinspired materials such as a polysaccharide to improve the stability of the NPs, ${ }^{7}$ or by using a catechin-derivative ${ }^{8}$ to allow pH-dependent stability against aggregation in liquid suspension prior to biological experimentation. In the search for a bioavailable and bioactive, yet non-toxic form of Se, red $\mathrm{Se}^{0} \mathrm{NPs}$, which were synthesized in the presence of and stabilized by bovine serum albumin (BSA), were orally administered to rats. The results showed a high degree of bio-activity comparable with that of Se(Iv) as Se-dependent enzymes were up-regulated, yet the acute and short-term toxicities were lower than that of $\mathrm{Se}(\mathrm{Iv}) .{ }^{9,10}$ In order to further investigate its potential as a chemopreventive agent, the toxicity of $\mathrm{Se}^{0} \mathrm{NPs}$ was compared with that of selenomethionine (SeMet) ${ }^{11}$ or methylselenocysteine (MeSeCys) in a short-term study with mice. ${ }^{12}$ The results showed less toxicity of the nanoform, and $\mathrm{Se}^{0} \mathrm{NPs}$ were as efficient as the two molecular Se forms in inducing the formation of Se-dependent enzymes. In a sub-chronic toxicity study with rats, the nano-Se source was inferior in toxicity to that of Se(Iv) or Se-rich protein used as sources of Se. ${ }^{13}$ Combined these results demonstrated a beneficial, lower acute and sub-chronic toxicity of $\mathrm{Se}^{0}$. When used as a feed additive $\mathrm{Se}^{0}$ NPs improved the intrinsic immunedefense system of sheep, rumen fermentation as well as utilization of the animals' feed. ${ }^{14,15}$

Regarding the Se retention in blood and tissues of experimental animals, no significant difference in the selenium concentration in blood, liver and kidneys was observed after 7 days of repeated administration of $\mathrm{Se}^{0} \mathrm{NPs}$ or MeSeCys to mice at nutritional levels (0.035 and $0.070 \mathrm{mg} \mathrm{kg}^{-1}$ bw per day). However, when administering a supra-nutritional dose ( $1 \mathrm{mg} \mathrm{kg}^{-1}$ bw per day) the Se concentration was higher in the MeSeCys exposed animals. ${ }^{12}$ Similar observations have been made when comparing $\mathrm{Se}^{0} \mathrm{NPs}$ with SeMet. ${ }^{11}$

Methods for detection and quantitative determination of $\mathrm{Se}^{0}$ in liquid suspension included reaction of the $\mathrm{Se}^{0}$ analyte with a sulfide followed by spectrophotometric absorbance measurements of the reaction product. ${ }^{16}$ A method for determination of $\mathrm{Se}^{0}$ in liver homogenates and in red blood cell lysates was based on the reduction of $\mathrm{Se}^{0}$ by sodium sulfite to form the selenosulfate-ion $\left(\mathrm{SeSO}_{3}{ }^{2-}\right)$. The concentration of $\mathrm{Se}^{0} \mathrm{NPs}$ was calculated from the difference in Se concentration in the sample (no sulfite treatment) and that in the supernatant of the sulfite-treated sample. ${ }^{12}$ The indirect nature of this analytical approach would benefit from a more direct method of analysis for the $\mathrm{SeSO}_{3}{ }^{2-}$ reaction product.

The aim of the present study was to investigate the absorption, distribution, metabolism and excretion (ADME) of $\mathrm{Se}^{0} \mathrm{NPS}$ stabilized with BSA in rats that were repeatedly exposed via oral gavage for 28 days. Two doses of Se, one close to physiological dose at $0.05 \mathrm{mg}$ Se per $\mathrm{kg}$ bw per day or one supra-nutritional dose at $0.5 \mathrm{mg}$ Se per $\mathrm{kg}$ bw per day, were administered daily. For comparison Se(Iv) was used as positive control. In order to most accurately describe the ADME of Se, its concentrations were determined in selected tissues, feces and urine using state-of-the-art mass spectrometric methods of analysis for Se and Se species analysis. Dynamic light scattering (DLS) or TEM were used for characterization of the particle size in the $\mathrm{Se}^{0} \mathrm{NP}$ suspension prior to dosage.

\section{Experimental}

\section{Selenium nanoparticles and chemicals}

A suspension of red amorphous $\mathrm{Se}^{0} \mathrm{NPs}$ was synthesized by reduction of sodium selenite with glutathione in the presence of BSA as described in detail elsewhere. ${ }^{9}$ A solution of $0.2 \mathrm{M}$ sodium sulfite (BRR, Prolabo, Leuven, Belgium) was prepared in ultra-pure water, which was obtained from a Millipore Element apparatus (Millipore, Milford, MA, USA). The $\mathrm{pH}$ of the freshly prepared solution was 9.5. The solvents used for the high performance liquid chromatography (HPLC) analyses were freshly He-degassed ultrapure water and methanol (Rathburn Chemicals Ltd., Walkerburn, Scotland). Solutions of selenocystine $\left(\mathrm{SeCys}_{2}\right)$ (Sigma-Aldrich, Copenhagen, Denmark) and of selenodiglutathione (GSSeSG) (PharmaSe, Lubbock, TX, USA) were prepared in He-degassed ultra-pure water. Aqueous solutions of selenite ( $\mathrm{Se}(\mathrm{Iv})$ ), selenate (Se(vi)) and selenomethionine (SeMet) were prepared as described previously. ${ }^{17}$

\section{Characterization of the $\mathrm{Se}^{\mathrm{o}}$ nanoparticle suspension}

The concentration of $\mathrm{Se}$ in the suspension of $\mathrm{Se}^{0} \mathrm{NPs}$ was determined following digestion by nitric acid (see the following section on Se analysis) by inductively coupled plasma mass spectrometry (ICP-MS) (7500ce, Agilent Technologies, Japan) run in the collision-reaction cell (CRC) mode with $\mathrm{He}$ as interferencereducing cell gas. The content of non-particulate Se in the suspension was determined following filtration through a $12 \mathrm{kDa}$ molecular weight cut-off cartridge (VectaSpin Micro Centrifuge Filter, Whatman, England) at $13400 \mathrm{rpm}(12100 \times g)$ for 10 minutes in a microcentrifuge (Eppendorf MiniSpin, Eppendorf AG, Hamburg, Germany). After digestion the acidic samples were diluted with a mixture of ultra-pure water and $3 \%$ methanol $^{18}$ to approximately $2 \%$ nitric acid concentration. The concentration of Se was quantified using external calibration with yttrium (Y) as the internal standard (SCP Science, Quebec, Canada). The limit of detection (3s) was 17 and $2 \mu \mathrm{g}$ Se per $\mathrm{mL}$ for the suspensions and filtrates, respectively.

The size distribution of each produced batch was determined by DLS and laser Doppler velocimetry was used for characterization of zeta-potential of the nanoparticles in suspension using a Zetasizer Nano-ZS (Malvern Instruments, UK). After equilibration of the sample to a temperature of $25{ }^{\circ} \mathrm{C}$, five measurements were performed with 12 runs of 10 seconds each. The laser power (attenuator index) and the measurement position within 
the cuvette were determined automatically by the instrument. For the calculation of the nanoparticle size distribution the viscosity of water was used. The optical parameters for selenium's index of refraction $n=3.37$ and index of absorption $k=0.52$ at $633 \mathrm{~nm}$ were applied. ${ }^{19}$

The size and shape of the $\mathrm{Se}^{0} \mathrm{NPs}$ were imaged by TEM using a TEM Philips CM100 instrument (FEI, Eindhoven, The Netherlands) at $80 \mathrm{kV}$ accelerating voltage. Prior to recording, the $\mathrm{Se}^{0} \mathrm{NP}$ suspension was diluted 10 times with deionized water. A drop of the suspension was applied to a formvar-coated copper grid.

\section{Instrumentation}

For the chromatographic separation of Se species, the HPLC flow was delivered using a quaternary, metal-free HPLC pump and an autosampler. Details of the anion exchange chromatographic system used for $\mathrm{SeSO}_{3}{ }^{2-}$ separations, the heparin-affinity HPLC system used for SelP analysis and the reversed-phase or cation exchange HPLC systems used for urine metabolites ${ }^{20,21}$ are given in ESI, $\dagger$ Table S1. Integration of chromatographic peaks was carried out using Total Chrom software version 6.3. For the lowlevel Se determinations in tissues, and for Se detection following HPLC separations, the ELAN 6100 ICP-DRC-MS instrument (Perkin Elmer SCIEX, Concord, Ont., Canada) was used in the dynamic reaction cell (DRC) mode for reduction of polyatomic interferences on ${ }^{77} \mathrm{Se},{ }^{78} \mathrm{Se}$ and ${ }^{80} \mathrm{Se}$. For Se speciation in urine ${ }^{82}$ Se was monitored using an ELAN 6000 ICP-MS instrument. Instrumental details for ICP-DRC-MS and for HPLC instrumentation were as described previously. ${ }^{22,23}$

\section{Animal study}

Four week old female Wistar Hannover Galas rats with a specific pathogen-free health status were purchased from M\&B Taconic (Lille Skensved, Denmark). Upon arrival the rats were allowed to acclimatize for a week before the start of the experiment. The body weight of the animals at the beginning of the study was (mean \pm one s.d.) $132 \pm 15 \mathrm{~g}(N=44)$. The rats were housed conventionally with two animals per cage (Macrolon, Techniplats Gazzada S. ar. L., Buguggiate, Italy) with a 12:12 h reversed light-dark cycle from 7 p.m. to 7 a.m. The room temperature was $22 \pm 1{ }^{\circ} \mathrm{C}$ and the relative humidity was $55 \% \pm 5 \%$. The rats were given ad libitum a standard diet (Altromin rat No.1324, Brogården, Gentofte, Denmark) and citric acid acidified ( $\mathrm{pH} 3$ ) tap water to avoid microbiological contamination of drinking water. The composition of the standard feed provided the animals with all necessary nutrients including an intake of vitamin $\mathrm{E}$ of $5.7 \mathrm{mg} \mathrm{kg}{ }^{-1}$ bw per day. The animal study was performed under conditions approved by the Danish Animal Experiments Inspectorate and the in-house Animal Welfare Committee. The rats were randomized into six groups, two of which during 28 consecutive days once daily orally by gavage received $100 \mathrm{~mL} \mathrm{~kg}{ }^{-1}$ bw of either deionized water $(N=8)$ or $100 \mathrm{~mL} \mathrm{~kg}^{-1}$ bw of an aqueous solution of $4 \mathrm{~g} \mathrm{~L}^{-1}$ of bovine serum albumin $(N=8)$ as vehicle controls (St. Louis, MO, USA). The BSA-stabilized suspensions of $\mathrm{Se}^{0} \mathrm{NPs}$ were dosed at 0.05 or $0.5 \mathrm{mg}$ Se per $\mathrm{kg}$ bw per day ( $N=6$ per group), or aqueous solutions of the Se(Iv) sodium salt were dosed at the same two doses ( $N=8$ per group). On day 15 of the study the rats were placed individually for 24 hours in metabolism cages for collection of urine and feces on dry ice. During this time the animals had access to water, but not to feed. On day 28 the rats were fasted overnight before euthanization on day 29 where they were anaesthetized in $\mathrm{CO}_{2} / \mathrm{O}_{2}$ and decapitated. Blood from the neck wound was collected on heparin and plasma was prepared by centrifugation $\left(1000 \times g\right.$ at 0 to $4{ }^{\circ} \mathrm{C}$ for $\left.10 \mathrm{~min}\right)$ and organs were removed. From six animals from each of the groups exposed to $0.5 \mathrm{mg} \mathrm{kg}{ }^{-1}$ bw per day of $\mathrm{Se}^{0} \mathrm{NPs}$ or $\mathrm{Se}(\mathrm{Iv})$, the stomach (corpus ventriculi), muscle (right biceps femoris) and brain, which were transferred to ice-cold $0.32 \mathrm{M}$ sucrose and homogenized by focused ultrasound, were reserved for chemical analysis. From the same animals, the liver (lowest part of the left median lobe), left kidney and feces were sampled for total Se and $\mathrm{Se}^{0}$ analysis, whereas blood plasma was subjected to total Se and SelP analysis.

\section{Sample preparation and analysis of Se, SelP and elemental Se}

Sub-samples of animal organs were mixed with nine times excess of ultra-pure water in a $50 \mathrm{~mL}$ polyethylene tube and homogenized using an Ultra Turrax homogenizer (DI 25 Basic, Ika-Werke, Staufen, Germany). The homogenates were frozen and stored at $-18{ }^{\circ} \mathrm{C}$ until time of analysis. The complete feces were collected and dried at $80{ }^{\circ} \mathrm{C}$ for 4 days. The dry samples were homogenized using a mortar and pestle and stored in a desiccator until time of analysis. The content of Se in the biological samples, in the $\mathrm{Se}^{0} \mathrm{NP}$-suspension and in the filtrates were determined by ICP-DRC-MS following microwave-assisted wet-ashing by nitric acid of $300 \mathrm{mg}$ of tissue, $100 \mathrm{mg}$ of feces or $1 \mathrm{~mL}$ of urine using a methodology described previously. ${ }^{17}$

The thawed blood plasma samples were passed through a $0.45 \mu \mathrm{m}$ filter (Whatman Mini-UniPrep, Clifton, NJ, USA) and subjected to separation of the SelP by heparin affinity HPLC (Table S1, ESI $\dagger$ ). Quantification was carried out using post-column isotope dilution using an enriched $(99.2 \%){ }^{77}$ Se standard. ${ }^{24}$ The enriched isotope (10 $\mathrm{ng}$ Se per $\mathrm{mL}$ using mobile phase A as solvent) was pumped using a peristaltic pump and its accurate flow was monitored daily by weighing. The enriched stable isotope and the eluent from the HPLC column were mixed via a T-piece before entry into the nebulizer of the ICP-DRC-MS, which was used to detect the spike isotope $\left({ }^{77} \mathrm{Se}\right)$ and the reference isotope $\left({ }^{80} \mathrm{Se}\right)$ at $50 \mathrm{~ms}$ dwell time per mass for the duration of the chromatographic separation. Corrections were made daily for mass bias.

Then thawed urine samples were diluted $(1+1)$ by the mobile phase and filtered prior to analysis. The separated Se species were quantified by external calibration by use of a single authentic standard of the respective Se species as the calibrant.

For control of accuracy of Se analyses in organs and feces the certified reference material (CRM) Bovine Liver (BCR CRM 185R No. 69, Geel, Belgium) with a certified value for Se of $1680 \pm 140 \mathrm{ng} \mathrm{g}^{-1}$ was included in each batch of analyses. The values obtained were corrected for the dry matter content of $93.2 \%$. For determination of $\mathrm{Se}$ in urine samples the RM Seronorm ${ }^{\mathrm{TM}}$ Trace Elements Urine (Nycomed Pharma 
Diagnostics, Oslo, Norway) with a reference value for Se of $58.6 \mathrm{ng}$ Se per mL was used.

For the in situ synthesis of the ion in tissues and feces, $500 \mu \mathrm{L}$ of the organ homogenate or $50 \mathrm{mg}$ of the dry feces containing $\mathrm{Se}^{0}$ were mixed with $250 \mu \mathrm{L}$ of the $0.2 \mathrm{M}$ sulfite solution and water to a final volume of $1500 \mu \mathrm{L}$. The mixture was placed in a flat bottom glass vial in a water bath at $50{ }^{\circ} \mathrm{C}$ for 20 minutes using magnetic stirring. After cooling, the mixture was purified by passage through a disposable $\mathrm{C}_{18}$ filter cartridge mounted in series with a membrane filter with a $0.45 \mu \mathrm{m}$ pore size. Prior to HPLC analysis, sub-samples of one for every ten of the sulfite-treated control samples were spiked with 0,100 or $200 \mathrm{ng}$ Se per $\mathrm{mL}$ as $\mathrm{Se}(\mathrm{vI})$, which was co-chromatographed and used to construct a standard additions calibration curve for Se on the basis of chromatographic peak area. Anion exchange HPLC (Table S1, ESI $\dagger$ ) was used to separate the synthesized $\mathrm{SeSO}_{3}{ }^{2-}$, which corresponded to the original content of $\mathrm{Se}^{0}$, from the spiked $\mathrm{Se}(\mathrm{vI})$ calibrant and other naturally occurring Se-species in the sample.

The contents of Se or Se species in the biological materials were compared using Student's two sample $t$-test $(p<0.05)$ after the $F$-test of the equality of variances (Excel, Microsoft Corporation, WA, USA).

\section{Results and discussion}

\section{$\mathrm{Se}^{\mathrm{o}}$ nanoparticle characterization}

The size distribution of the $\mathrm{Se}^{0} \mathrm{NPs}$ in BSA solution determined by DLS is shown in Fig. 1. The major fraction of the nanoparticles had a diameter in the range of 10 to $80 \mathrm{~nm}$ with a maximum of the size distribution (mean \pm one s.d.) at $19 \pm$ $1 \mathrm{~nm}$. A small fraction of the $\mathrm{Se}^{0} \mathrm{NPs}$ was present as micrometer sized aggregates, which could not be dispersed by ultrasound. The size distribution was determined immediately before and after the animal study to ensure that nanoparticles with the same size characteristics were administered to the rats throughout the animal study. Transmission electron microscopy (Fig. 1) confirmed the determined diameter and showed that the particles had a spherical shape. The total selenium concentration in the suspensions was (mean \pm one s.d.) $380 \pm$ $3 \mu \mathrm{g} \mathrm{mL}{ }^{-1}$. The amount of unbound selenium was undetectable

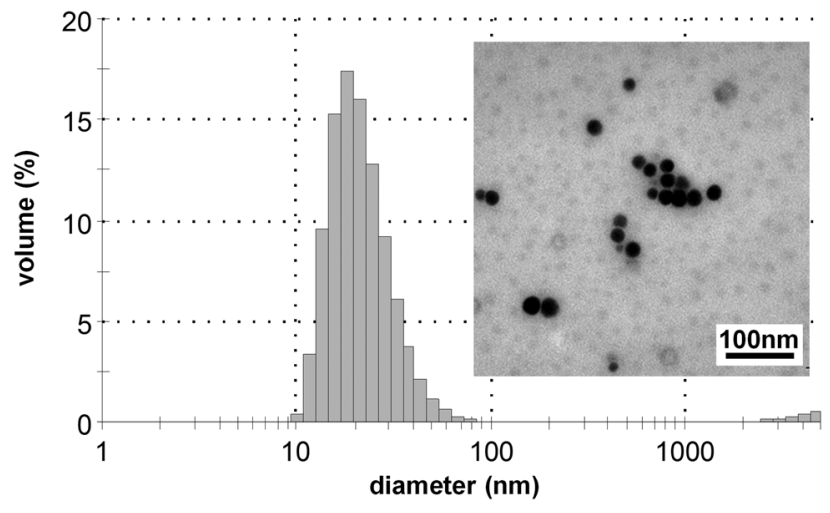

Fig. 1 Size characterization of $\mathrm{Se}^{0} \mathrm{NPs}$ by DLS and TEM. $\left(<2 \mu \mathrm{g} \mathrm{mL} \mathrm{m}^{-1}\right)$ showing that all administered Se was in the form of nanoparticles.

\section{Absorption and distribution of Se}

The animal study included two Se dose levels for each chemical form, i.e. $\mathrm{Se}^{0} \mathrm{NPs}$ and $\mathrm{Se}(\mathrm{Iv})$. The low dose at $0.05 \mathrm{mg}$ Se per $\mathrm{kg}$ bw per day was chosen as toxicological effects were not expected, and the high dose at $0.5 \mathrm{mg}$ Se per $\mathrm{kg}$ bw per day was chosen as a supra-nutritional dose where toxicological effects were likely to occur. ${ }^{12,13}$ The intrinsic Se concentration in the rats' feed was (mean \pm one s.d.) $250 \pm$ $54 \mathrm{ng} \mathrm{g}^{-1}(N=3)$, which influenced the Se content in the control animals. Considering an average consumption of feed for a rat of around $15 \mathrm{~g}$ per day, the control animals received about $0.03 \mathrm{mg}$ Se per $\mathrm{kg}$ bw per day via the feed. The distribution of Se in a range of organs, blood plasma, urine and feces from rats, that were administered the highest dose, and in corresponding controls, was analyzed by ICP-DRC-MS (Fig. 2). The largest concentrations were detected in the metabolically active organs liver and kidneys. The Se contents in most biological samples were not different for the two dosage forms. In lungs however, the Se content was higher following dosage with Se(Iv), but the reason for this slightly higher content remains unknown. The results in Fig. 2 demonstrated that the bioavailability in rats of $\mathrm{Se}^{0} \mathrm{NPs}$ was similar to that observed for Se(Iv) as indicated by the plasma concentrations. For the animals, which received $0.5 \mathrm{mg}$ Se per $\mathrm{kg}$ bw per day the recovery of Se in their feces amounted to (mean \pm one s.d.) $12 \pm 5 \%$ and $13 \pm 5 \%$ of the daily doses of $\mathrm{Se}^{0}$ or $\mathrm{Se}(\mathrm{Iv})$, respectively. The similar urinary excretions were $45 \pm 4 \%$ and $53 \pm 10 \%$ of the daily doses.

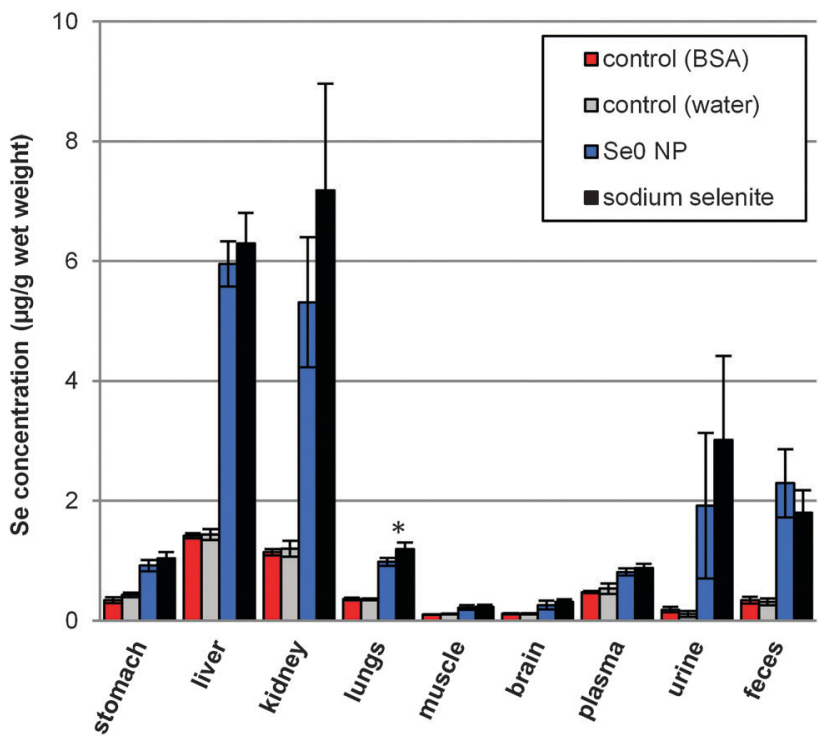

Fig. 2 Se concentrations (mean \pm s.d.) in rat organs, blood plasma, feces and urine following administration of $0.5 \mathrm{mg}$ Se per $\mathrm{kg}$ bw per day. All values were significantly different from corresponding controls ( $p<0.001$ ). For lungs the Se values following dosage of Se(Iv) were higher $(p=0.002)$ than those following dosage of $\mathrm{Se}^{0} \mathrm{NP}$ 
Analysis and occurrence of $\mathrm{Se}^{\mathrm{0}}$ in liver, kidneys and feces

Given the finding that both administered Se forms were absorbed by rats, the question was in which chemical or physical form it was present. Bearing in mind that intact selenium nanoparticles were reported in livers following oral administration of BSA-stabilized $\mathrm{Se}^{0} \mathrm{NPs}$ to mice, ${ }^{12}$ it was decided to test if $\mathrm{Se}^{0}$ occurred in the organs from the present work. The most straightforward way would be to apply an imaging method and screen for the presence of $\mathrm{Se}^{0} \mathrm{NPs}$. Given that the mean diameter of the dosed $\mathrm{Se}^{0} \mathrm{NPs}$ was approximately $20 \mathrm{~nm}$ and that the liver tissue concentration of Se was approximately $5 \mu \mathrm{g} \mathrm{g}^{-1}$, the number density however, was too low for any successful imaging of $\mathrm{Se}^{0} \mathrm{NPs}$ by TEM. Therefore, anion exchange HPLC-ICP-MS was used following in situ derivatisation of $\mathrm{Se}^{0}$ with sulfite to $\mathrm{SeSO}_{3}{ }^{2-1} \cdot 12,25,26$

The usefulness of the method based on in situ derivatisation of $\mathrm{Se}^{0}$ in biological materials depended on its selectivity, accuracy and on possible associated matrix effects. In order to test the selectivity of the derivatisation method to $\mathrm{Se}^{0}, \mathrm{Se}$ species that are known to occur in biological materials, and therefore could interfere during the sulfite reaction, were taken through the derivatisation procedure and the reaction product analysed by anion-exchange HPLC-ICP-MS. The results in Fig. 3 demonstrated that the method was selective to $\mathrm{Se}^{0}$, with the exception of GSSeSG for which a small HPLC peak co-eluted with the reaction product between $\mathrm{Se}^{0} \mathrm{NPs}$ and sulfite, i.e. $\mathrm{SeSO}_{3}{ }^{2-}$ (lower trace). This could be caused by instability of the selenotrisulfide, which was observed to degrade at neutral or alkaline $\mathrm{pH}$ followed by formation of elemental Se. ${ }^{27}$ The method was applied to the analysis of $\mathrm{Se}^{0}$ in the biological samples and an example chromatogram is shown in ESI, $\dagger$ Fig. S0. The influence of the reaction time between sulfite and $\mathrm{Se}^{0}$ on the yield of $\mathrm{SeSO}_{3}{ }^{2-}$ showed that reaction times longer than 20 minutes gave no further yield of this Se species, which was stable only for a few hours in the pre-treated biological tissue (ESI, $\dagger$ Fig. S1). The samples therefore had to be analyzed within a short time interval from the sample pre-treatment. Absolute recoveries of Se following spiking with $\mathrm{Se}^{0} \mathrm{NPs}$ to liver, kidneys or feces were $64-72 \%$, and possible matrix effects on the calibration curves based on spiking with $\mathrm{Se}(\mathrm{vI})$ were undetectable as shown in ESI, $\dagger$ Fig. S2.

The quantitative results for the content of $\mathrm{Se}^{0}$ in liver, kidneys and feces are given in Fig. 4 as a fraction of total Se in each biological sample. The results demonstrated that $\mathrm{Se}^{0}$ was indeed detected in the biological materials from animals following administration of $\mathrm{Se}^{0} \mathrm{NPs}$ or $\mathrm{Se}(\mathrm{Iv})$ at both dose levels. The intake of Se from the feed was $0.03 \mathrm{mg} \mathrm{kg}^{-1}$ bw per day, which yielded detectable $\mathrm{Se}^{0}$ at around $5-10 \%$ of the total Se concentration in the control samples. For the rats, which were dosed $0.05 \mathrm{mg} \mathrm{kg}{ }^{-1}$ bw per day, the liver and kidney samples also showed a content of $\mathrm{Se}^{0}$, which did not differ from the corresponding controls and did not depend on the dosage form. This suggested that the metabolic potential of Se in these organs was sufficient to convert the administered Se via natural pathways. In contrast, in the samples from rats, which were administered the ten times higher dose, i.e. $0.5 \mathrm{mg} \mathrm{kg}^{-1}$ bw per day, the
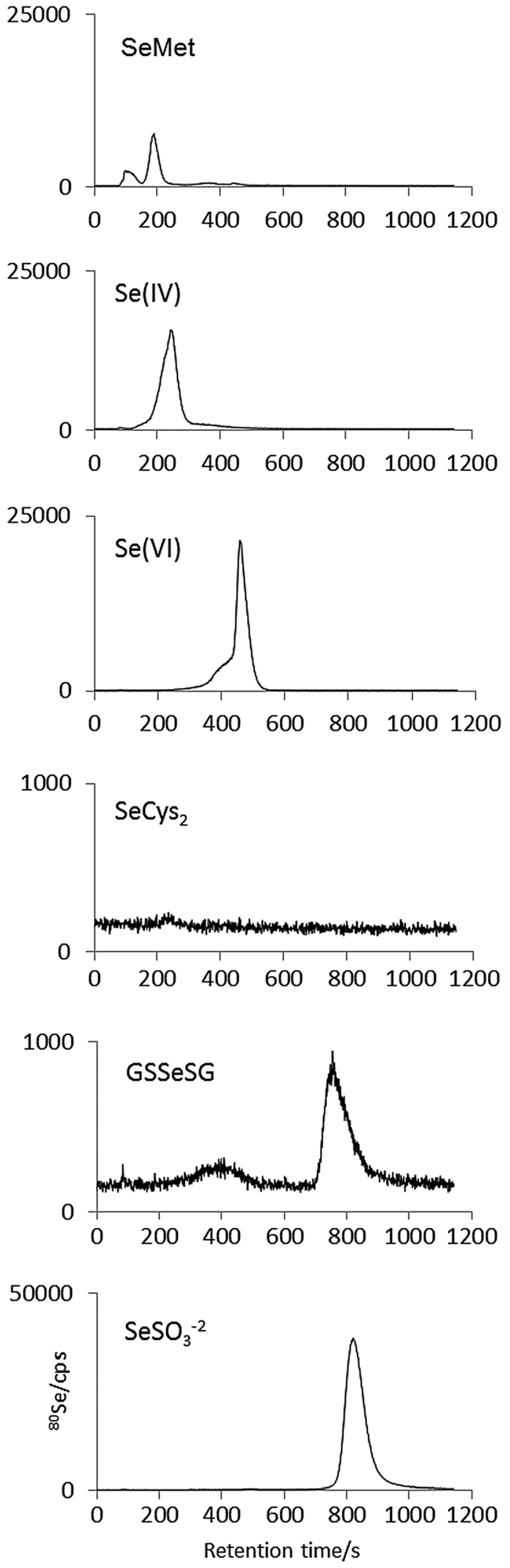

Fig. 3 Anion exchange HPLC-ICP-MS chromatograms of $150 \mathrm{ng}$ Se per $\mathrm{mL}$ of authentic Se standards, and $1000 \mathrm{ng}$ Se per $\mathrm{mL}$ of $\mathrm{Se}^{0} \mathrm{NPs}$ treated with sulfite leading to formation of $\mathrm{SeSO}_{3}{ }^{2-}$. See the Methods section for further details. 


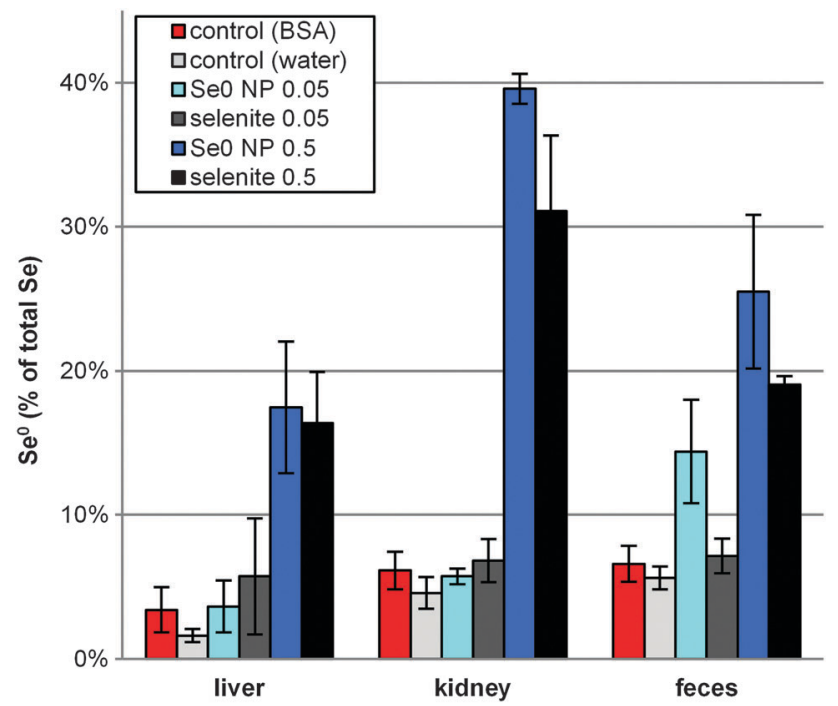

Fig. 4 Elemental $\mathrm{Se}\left(\mathrm{Se}^{0}\right)$ as a percent of total $\mathrm{Se}$ (mean \pm s.d.) in rat liver, kidneys and feces. Columns correspond to administration of $\mathrm{Se}^{0} \mathrm{NPs}$ or Se(Iv) (mg Se per kg bw per day) or controls.

relative amount of $\mathrm{Se}^{0}$ in liver and kidneys increased significantly from 2 to $7 \%$ in the control and low dose animals to between 17 and $40 \%$ of the total Se concentration in these organs. This increase could be explained by exhaustion of the natural reductive pathway by glutathione (GSH) leading to formation of $\mathrm{Se}^{0} v i a$ formation of unstable GSSeSG or selenopersulfide intermediates. ${ }^{2,28}$ Under such circumstances the risk of Se toxicity may be prevalent due to the associated possible oxidative damage. ${ }^{29}$ The relative excretion of $\mathrm{Se}^{0}$ in feces was generally higher from animals that received $\mathrm{Se}^{0} \mathrm{NPs}$ than those receiving $\mathrm{Se}(\mathrm{rv})$, which indicated a lower absorption of $\mathrm{Se}^{0} \mathrm{NPs}$. The finding of $\mathrm{Se}^{0}$ in the feces also from the Se(rv) dosed group of animals can be explained by bacterial reduction of $\mathrm{Se}(\mathrm{rv})$ to $\mathrm{Se}^{0} .^{30}$

\section{Selenoprotein $\mathrm{P}$ as a blood biomarker for exposure to $\mathrm{Se}^{\mathbf{0}} \mathrm{NPs}$}

The bioavailability and incorporation of Se into Se-proteins was monitored by SelP in plasma. Because synthesis of selenoproteins occurs as part of the suggested metabolic pathway of Se in animals and humans, the up-regulation is considered to express that both forms of administered Se were available to the pathway. ${ }^{1}$ The content of SelP in plasma was analysed by affinity HPLC-ID-ICP-MS as shown by the example chromatogram in ESI, $\dagger$ Fig. S3. The final results were calculated on the basis of the ratio of ${ }^{77} \mathrm{Se}$ to ${ }^{80} \mathrm{Se}$. The results in Fig. 5 show for both dose levels of Se(Iv), that SelP was expressed to a higher concentration than that in the corresponding controls. Following the administration of two doses of $\mathrm{Se}^{0} \mathrm{NPs}$ to the rats however, this increase was observed only for the high dose of $0.5 \mathrm{mg} \mathrm{kg}^{-1} \mathrm{bw}$ per day. Because the levels of SelP in plasma were not significantly different in the high dose $\mathrm{Se}^{0} \mathrm{NPs}$ group as compared with $\mathrm{Se}(\mathrm{Iv})$, it is concluded that both forms of Se are equally bioavailable and cause an equal up-regulation of SelP in rats. The same conclusion was drawn for the liver, plasma and kidney glutathione peroxidases (GPx) in mice

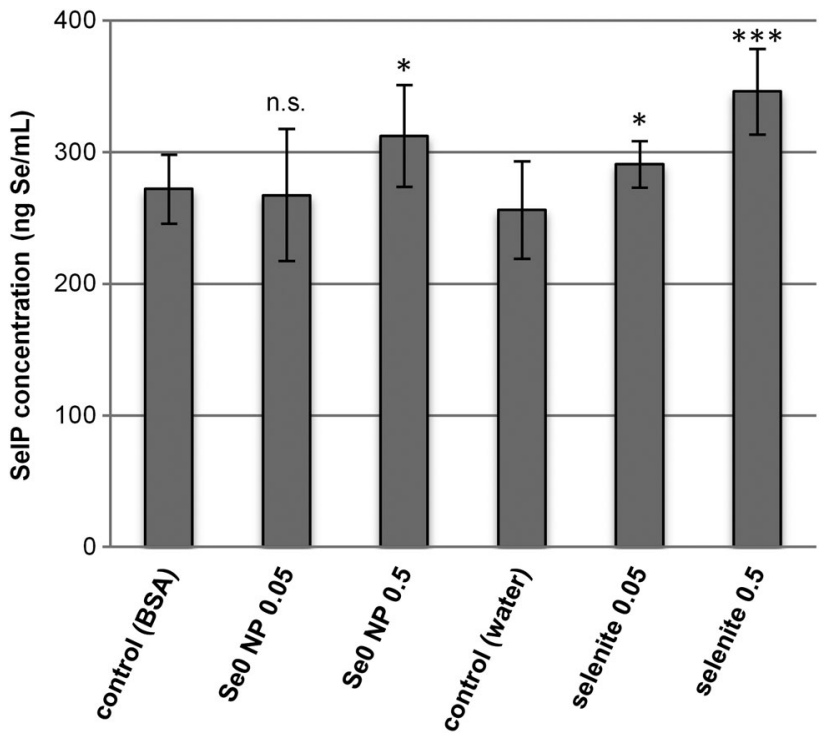

Fig. 5 Concentration of selenoprotein $\mathrm{P}(\mathrm{SelP})$ in rat plasma (mean \pm s.d.) following administration of $\mathrm{Se}$ as $\mathrm{Se}^{0} \mathrm{NPs}$ or $\mathrm{Se}(\mathrm{Iv})$ at low or high doses ( $\mathrm{mg} \mathrm{kg}^{-1}$ bw per day). The stars indicate the level of significant difference between dosage and control. The results corresponding to high doses of $\mathrm{Se}^{0} \mathrm{NP}$ and $\mathrm{Se}(\mathrm{Iv})$ were not significantly different.

supplemented with $\mathrm{Se}^{0} \mathrm{NPs}$ or $\mathrm{Se}(\mathrm{rv})$, but for up-regulation of thioredoxin reductases (TrxR) in liver and kidneys, Se(rv) was more efficient than $\mathrm{Se}^{0} \mathrm{NPs} .{ }^{9,12}$ The present findings in rats and the previously published results for mice indicate that the investigated Se-proteins were up-regulated dependent on the supplemented dose of Se, but largely independent of its chemical form.

\section{Excretion of Se in urine}

The excretion of Se (Fig. 2) and Se species metabolites was studied in urine by HPLC-ICP-MS. Despite the fact that the level of the glutathione may have been influenced by the animals' fasting at the day of collection of urine, and knowing that this reductant influences the metabolism of Se in rats, still the state of fasting is relevant both to animals and to humans e.g. while sleeping, or after the postprandial period. Representative chromatograms (ESI, $\uparrow$ Fig. S4) show that the selenosugar, Se-methylseleno- $N$-acetyl-galactosamine (SeGalNAc) and trimethylselenonium-ion $\left(\mathrm{TMSe}^{+}\right.$) were detected and the semi-quantitative results are presented in Fig. 6. It appears that for animals treated with $\mathrm{Se}^{0} \mathrm{NPs}$, the concentrations of SeGalNAc are higher in the low dose animals compared to high dose animals, while the opposite pattern was observed in the animals dosed with Se(rv). However, the variation between animals is very large. The results in Fig. 6 are given as urine concentrations, and calculation of total excreted Se did not change this pattern. No $\mathrm{TMSe}^{+}$was detected in controls and low dose animals, while large amounts were observed in both high dose groups. When calculating the percentage of Se excreted as SeGalNAc and $\mathrm{TMSe}^{+}$, respectively (ESI, $\dagger$ Table S2), it appeared that in low dose animals that received both Se forms and in controls, about $70 \%$ of the Se content was excreted as SeGalNAc, while the average excretion of this se species in high dose animals was around $20 \%$. 


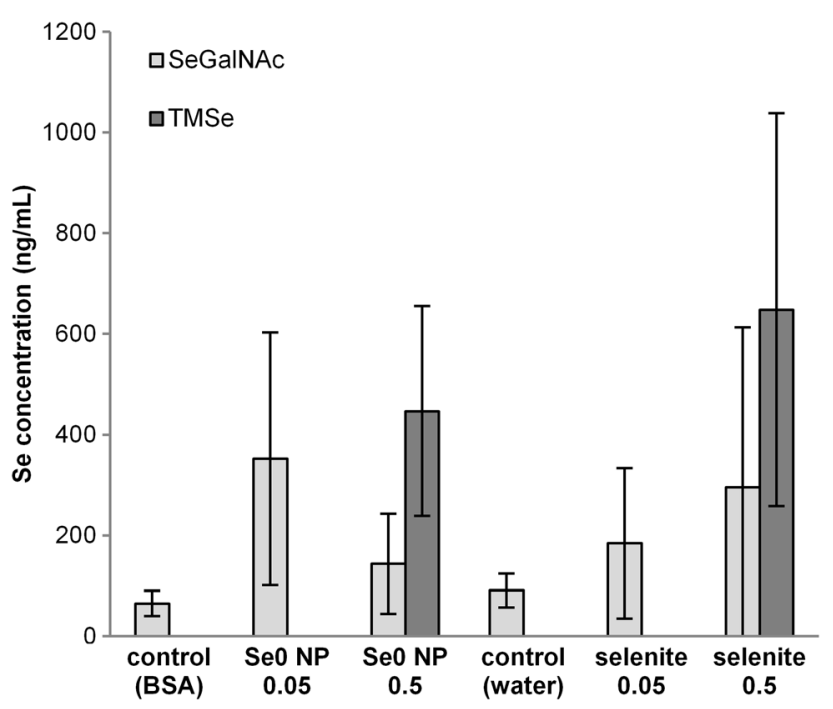

Fig. 6 Concentration of Se-methylseleno- $N$-acetyl-galactosamine and trimethylselenonium-ion in rat urine following administration of $\mathrm{Se}^{0} \mathrm{NPs}$ or Se(Iv).

At the same time the $\mathrm{TMSe}^{+}$excretion increased to about $50 \%$ in both high dose groups. Thus, the average excretion patterns of SeGalNAc and $\mathrm{TMSe}^{+}$were identical after $\mathrm{Se}^{0} \mathrm{NP}$ or $\mathrm{Se}$ (Iv) administration. SeGalNAc is the major metabolite in urine, ${ }^{31,32}$ while the presence of $\mathrm{TMSe}^{+}$is dose dependent in rats. ${ }^{33}$ The finding that the relative $\mathrm{TMSe}^{+}$excretion increases with increasing doses of selenite in rats is thus in accordance with previous results for young rats, ${ }^{33}$ although the studies on groups of animals are limited and no speciation data on Se excretion after $\mathrm{Se}^{0} \mathrm{NP}$ administration have been published before.

\section{Possible conversions of Se in the gastro-intestinal tract of rats prior to absorption}

Following oral administration by gavage of Se as $\mathrm{Se}^{0} \mathrm{NPs}$ or $\mathrm{Se}(\mathrm{Iv})$ the dosed forms may undergo changes under the influence of the different physico-chemical and microbial conditions existing in the compartments of the gastrointestinal tract of rats. The similar concentration of Se found in the blood and the organs following oral administration of $\mathrm{Se}$ as $\mathrm{Se}^{0} \mathrm{NPs}$ or $\mathrm{Se}$ (Iv) (Fig. 2) and the similar fraction of $\mathrm{Se}^{0}$ herein (Fig. 4) suggest that the two chemical forms were metabolized following similar pathways.

Such pathways may include that $\mathrm{Se}(\mathrm{Iv})$ was reduced to $\mathrm{Se}^{0}$, or that $\mathrm{Se}^{0} \mathrm{NPs}$ became dissolved and oxidized to inorganic oxoanions of Se, as both reactions were possible in a microbial environment. ${ }^{3,34}$ Such conversions were demonstrated using the intestinal contents from rats as medium and it was shown that $\mathrm{Se}(\mathrm{Iv})$ was reduced to red elemental $\mathrm{Se}^{0}$ by the gut microflora. ${ }^{30} \mathrm{In}$ a study with broiler chickens, the animals were dosed with ${ }^{75} \mathrm{Se}$ (Iv) or as BSA-stabilized ${ }^{75} \mathrm{Se}^{0} \mathrm{NPs}$ at approximately the same size as used in the present study. ${ }^{35}$ The results showed that the nanoparticles were more effectively absorbed by the chickens in comparison with Se administered as Se(Iv). The authors suggested that the $\mathrm{Se}^{0} \mathrm{NPs}$ were absorbed directly from the intestine, but did not present any direct evidence to support this.
Alternatively, the dosed BSA-stabilized $\mathrm{Se}^{0} \mathrm{NPs}$ may become dissolved in oxidized segments of the gastrointestinal tract and possibly form Se(Iv) via microbial or chemical activity. ${ }^{35}$ In this case, Se(Iv) would be absorbed passively in a similar fashion for both dosage forms, and such a route would support our findings. Furthermore, the slightly higher content of Se and higher proportion of $\mathrm{Se}^{0}$ in feces from animals given the $\mathrm{Se}^{0} \mathrm{NPs}$ in this study (Fig. 2) lends credit to this fate of $\mathrm{Se}^{0} \mathrm{NPs}$ in rats.

\section{Conclusions}

In conclusion, our studies have shown that Se from $\mathrm{Se}^{0} \mathrm{NPs}$ was absorbed and distributed to organs and excreted to the same extent as that observed for Se administered as Se(Iv) used as positive control. The bioavailability of nanoparticulate elemental Se was derived from the finding of SelP in plasma. The entry of $\mathrm{Se}^{0} \mathrm{NPS}$ into the metabolic pathway and its subsequent excretion was proven by the detection of the urinary metabolites Se-methylseleno- $N$-acetylgalactosamine and $\mathrm{TMSe}^{+}$and furthermore indicated by the similar excretion patterns in rats' urine after dosage of $\mathrm{Se}^{0} \mathrm{NPs}$ or $\mathrm{Se}(\mathrm{Iv})$. The high relative amount (tens of percent) of $\mathrm{Se}^{0}$ found in liver and kidneys of animals receiving the high dose of $\mathrm{Se}^{0} \mathrm{NPs}$ or $\mathrm{Se}(\mathrm{Iv})$ suggested a dissimilarity in metabolism in the animals that received low dose or controls. The possible toxic reaction associated with the high dose triggered further study of selenium toxicity following exposure to $\mathrm{Se}^{0} \mathrm{NPs}$, which is now underway in our group. The fate and mechanisms behind the possible conversions of Se in the gastrointestinal tract of rats to shed light on which pathways are active prior to absorption need further elucidation. The aim of such research would be to answer the question whether Se dosed as Se(Iv) is reduced to $\mathrm{Se}^{0}$ and absorbed as such, or whether $\mathrm{Se}^{0}$ becomes oxidized to oxo-anions of Se before absorption.

\section{Acknowledgements}

The authors wish to thank the Danish Food Industry Agency for funding the project. Anne Ørngreen, Maja Danielsen, Eva Ferdinansen, Elise E. Navntoft, Eigil V. Frank, Kenneth R. Worm and Sarah G. Simonsen are thanked for excellent technical assistance. Finally, we thank Dr Xueyun Gao, Institute for High Energy Physics, Chinese Academy of Sciences, Beijing, China for skillful synthesis of the BSA-stabilized $\mathrm{Se}^{0} \mathrm{NPs}$.

\section{References}

1 C. Thiry, A. Ruttens, L. De Temmerman, Y. J. Schneider and L. Pussemier, Food Chem., 2012, 130(4), 767-784.

2 H. E. Ganther, Biochemistry, 1971, 10(22), 4089-4098.

3 P. R. Dowdle and R. S. Oremland, Environ. Sci. Technol., 1998, 32(23), 3749-3755.

4 M. M. Gharieb, S. C. Wilkinson and G. M. Gadd, J. Ind. Microbiol., 1995, 14(3-4), 300-311.

5 S. K. Xia, L. Chen and J. Q. Liang, J. Agric. Food Chem., 2007, 55(6), 2413-2417. 
6 G. Combs, C. Garbisu, B. Yee, A. Yee, D. Carlson, N. Smith, A. Magyarosy, T. Leighton and B. Buchanan, Biol. Trace Elem. Res., 1996, 52(3), 209-225.

7 H. Wu, X. Li, W. Liu, T. Chen, Y. Li, W. Zheng, C. W.-Y. Man, M. K. Wong and K. H. Wong, J. Mater. Chem., 2012, 22(19), 9602-9610.

8 S. Wu, K. Sun, X. Wang, D. Wang, X. Wan and J. Zhang, J. Agric. Food Chem., 2013, 61(30), 7268-7275.

9 J.-S. Zhang, X.-Y. Gao, L.-D. Zhan and Y.-P. Bao, BioFactors, 2001, 15(1), 27-38.

10 J. Zhang, H. Wang, X. Yan and L. Zhang, Life Sci., 2005, 76(10), 1099-1109.

11 H. Wang, J. Zhang and H. Yu, Free Radical Biol. Med., 2007, 42(10), 1524-1533.

12 J. Zhang, X. Wang and T. Xu, Toxicol. Sci., 2008, 101(1), 22-31.

13 X. Jia, N. Li and J. Chen, Life Sci., 2005, 76(17), 1989-2003.

14 S. Sadeghian, G. Kojouri and A. Mohebbi, Biol. Trace Elem. Res., 2012, 146(3), 302-308.

15 L. Shi, W. Xun, W. Yue, C. Zhang, Y. Ren, L. Shi, Q. Wang, R. Yang and F. Lei, Small Ruminant Res., 2011, 96(1), 49-52.

16 K. C. Biswas, L. L. Barton, W. L. Tsui, K. Shuman, J. Gillespie and C. S. Eze, J. Microbiol. Methods, 2011, 86(2), 140-144.

17 E. Kápolna, P. R. Hillestrøm, K. H. Laursen, S. Husted and E. H. Larsen, Food Chem., 2009, 115(4), 1357-1363.

18 E. H. Larsen and S. Stürup, J. Anal. At. Spectrom., 1994, 9(10), 1099-1105.

19 Handbook of Optical Constants of Solids, ed. E. D. Palik, Academic Press, Inc., 1991.
20 B. Gammelgaard, K. Jessen, F. Kristensen and O. Jøns, Anal. Chim. Acta, 2000, 404, 47-54.

21 B. Gammelgaard, L. Bendahl, N. W. Jacobsen and S. Stürup, J. Anal. At. Spectrom., 2005, 9, 889-893.

22 E. H. Larsen, J. Sloth, M. Hansen and S. Moesgaard, J. Anal. At. Spectrom., 2003, 18(4), 310-316.

23 J. J. Sloth, E. H. Larsen, S. H. Bügel and S. Moesgaard, J. Anal. At. Spectrom., 2003, 18(4), 317-322.

24 P. Rodríguez-González, A. Rodríguez-Cea, J. I. García Alonso and A. Sanz-Medel, Anal. Chem., 2005, 77(23), 7724-7734.

25 E. C. Pitzer and N. E. Gordon, Ind. Eng. Chem., Anal. Ed., 1938, 10, 0068-0069.

26 Y. Rodriguez-Lazcano, Y. Pena, M. T. S. Nair and P. K. Nair, Thin Solid Films, 2005, 493(1-2), 77-82.

27 C. Gabel-Jensen, B. Gammelgaard, L. Bendahl, S. Stürup and O. Jøns, Anal. Bioanal. Chem., 2006, 384(3), 697-702.

28 L. Margos and M. Webb, Crit. Rev. Toxicol., 1980, 8(1), 1-42. 29 J. E. Spallholz, Free Radical Biol. Med., 1994, 17(1), 45-64.

30 W. Krittaphol, A. McDowell, C. Thomson, M. Mikov and J. P. Fawcett, Biol. Trace Elem. Res., 2011, 139(2), 188-196.

31 K. T. Suzuki, J. Health Sci., 2005, 51, 107-114.

32 B. Gammelgaard, M. I. Jackson and C. Gabel-Jensen, Anal. Bioanal. Chem., 2011, 399(5), 1743-1763.

33 K. T. Suzuki, K. Kurasaki, N. Okazaki and Y. Ogra, Toxicol. Appl. Pharmacol., 2005, 206, 1-8.

34 R. S. Oremland, M. J. Herbel, J. S. Blum, S. Langley, T. J. Beveridge, P. M. Ajayan, T. Sutto, A. V. Ellis and S. Curran, Appl. Environ. Microbiol., 2004, 70(1), 52-60.

35 C. H. Hu, Y. L. Li, L. Xiong, H. M. Zhang, J. Song and M. S. Xia, Anim. Feed Sci. Technol., 2012, 177, 204-210. 